\title{
Structural analysis of historic masonries
}

\author{
Angeliki Papalou ${ }^{1}$, Maria E. Stavroulaki ${ }^{2}$ \\ ${ }^{I}$ Department of Renovation and Restoration of Buildings, T.E.I. of Patras, Greece \\ ${ }^{2}$ Applied Mechanics Laboratory, Sciences Department, Technical University of Crete, Greece \\ *Corresponding author E-mail: papalou@teipat.gr
}

\begin{abstract}
Several historic masonries have experienced severe damage and collapse due to lack of proper design and maintenance. Understanding of their behavior is essential for their survival. Multi-leaf walls, a special case that is often encountered in historic masonries, need special attention due to the complex geometry and its weak inner leaf. The behavior of historic masonries when subjected to different static load is investigated. An isolated multi-leaf wall is modeled using the finite element method. Multiple cases, varying the properties of the materials of the multi-leaf wall and loading conditions, are analyzed considering linear elastic behavior of the materials. It is found that the properties of the multileaf walls and the loads applied affect considerably the response of the structure.
\end{abstract}

Keywords: historic masonry, multi-leaf wall, structural analysis, finite element method

\section{Introduction}

Heritage structures are primarily made of masonry elements usually connected with mortar. Poor connection of the masonry elements, lack of proper maintenance and seismic activity can lead to deterioration, damage and even collapse of the wall. In order to correctly approach the maintenance of a historic masonry it is necessary to understand its response for future loading conditions. The multi-leaf wall is a special case of a historic wall. It usually consists of two outer leaves of stronger material and an inner one of weaker material. These types of walls are common in Western Europe where seismic events occur frequently. The weak material of the inner layer, the poor connection between the layers and the deterioration of mortar make the walls unstable and prone to damage.

The complexity of the geometry of the multi-leaf wall, the composition of the inner leaf and the variability of the properties of the materials make the analysis of this structure challenging. Previous work [1, 2, 3, 4, 5], based mainly on actual historical masonries, has provided valuable insight into the behaviour of these masonry structures. Further understanding of the behavior of the multi-leaf walls can be gained by examining the behavior of an isolated wall with varying leaf properties excited by different loading conditions.

This paper examines the behavior of multi-leaf structures for different static loading conditions. A parametric study is performed on multi-leaf walls based on the finite element method. The properties of the inner leaf (which is the weaker one) are altered as the structure is subjected to different static loads. Initially the inner leaf is subjected to increasing compressive load and the results obtained are compared with experimental measurements. Full section compression load is also applied considering different modulus of elasticity of the inner leaf. In addition to compression, shear load is applied and the response of the structure is examined for the combined loading conditions.

\section{The structural system}

To examine the influence of the properties of a three-leaf wall on its response to different loading conditions, we use in our model the same dimensions that Binda et al. [5] used in their experiments. The dimensions are: height $7.9 \mathrm{~m}$, length $5.1 \mathrm{~m}$, width $3.1 \mathrm{~m}$ and thickness of every leaf $1.7 \mathrm{~m}$ (Fig. 1). The wall is fixed at the base and the mortar joints are ignored assuming that each leaf is homogeneous. In addition, perfect bonding is assumed at the interface of each leaf. Linear elastic behavior of the materials is assumed. 


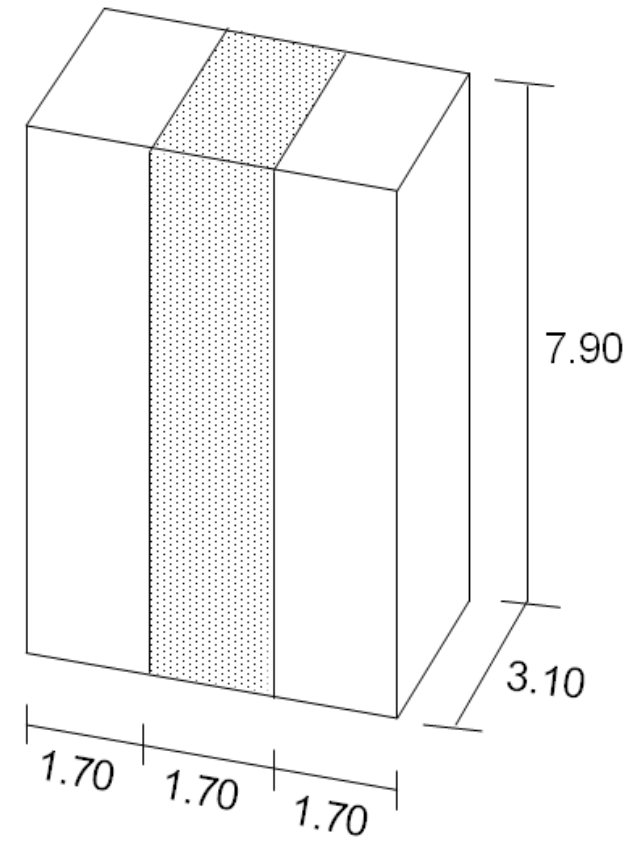

Fig. 1: Dimensions of model wall in $\mathrm{m}$.

The leaves of the wall are represented using solid 3-D 20 node elements (Figure 2). The properties of the outer leaves are the same having density $2100 \mathrm{~kg} / \mathrm{m}^{3}$ and Poisson ratio equal to 0.10 . The properties of the inner leaf are different than the outer: a density of $1800 \mathrm{~kg} / \mathrm{m}^{3}$ and a Poisson ratio of 0.15 is assumed.

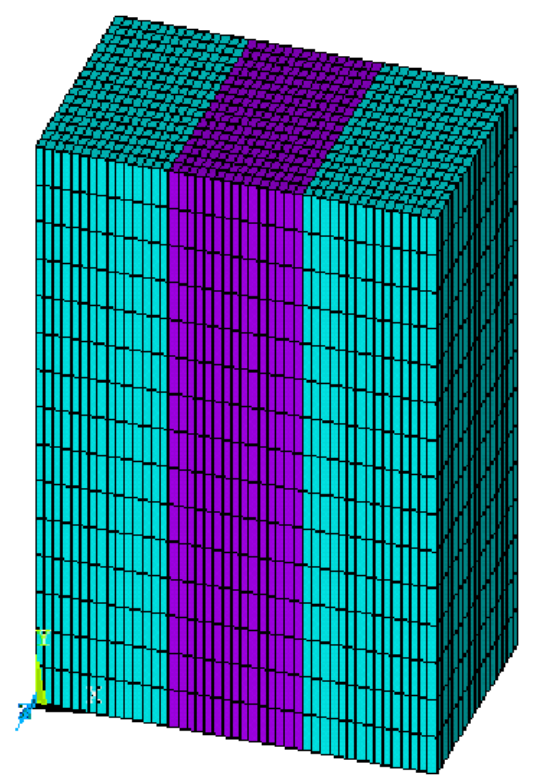

Fig. 2: Finite element model of the three-leaf wall.

The response of the three-leave wall to different properties of the material is examined by varying the modulus of elasticity of the inner leaf while keeping constant the modulus of elasticity of the outer ones. The two loading conditions considered include compression and a combination of compression and shear. Initially, the validity of the model is tested applying pressure only to the inner leaf and comparing the results obtained with the results reported by other researchers. 


\subsection{Evaluation of finite element model}

Compressive load is applied at the top of the inner leaf while the other ones are free of external load (self weight is included for all leaves). The magnitude of the compressive load varies from $0.3 \mathrm{MPa}$ to $10 \mathrm{MPa}$. To match the properties of the wall that Binda et al. [5] examined in their experiments the modulus of elasticity of the outer leaves is assumed to be $3150 \mathrm{MPa}$ and of the inner one $1830 \mathrm{MPa}$. Static analysis is performed for the different loading conditions. The results obtained are presented in Figure 3 and are compared with the measurements of Binda et al. [5]. The model predictions are quite close to the measurements up to the yield point. Since in this investigation linear elastic behavior of the materials is assumed the model cannot reproduce the system's behavior in the plastic region (Fig. 3).

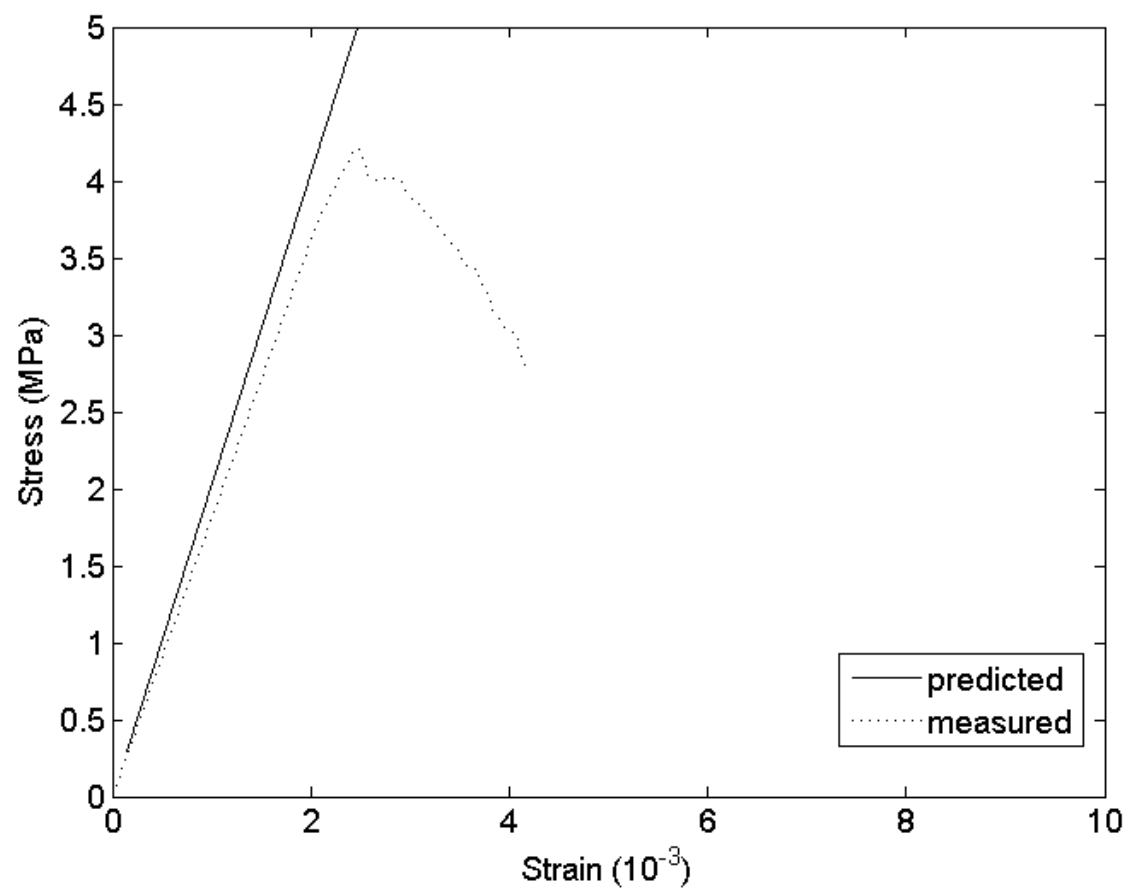

Fig. 3: Stress-strain diagram obtained from compression of the inner leaf. Finite element model predictions and measurements by Binda et al [5].

\subsection{Compressive load}

The influence of the modulus of elasticity on the behavior of the multi-leaf wall is initially examined for a compressive load applied at the top of the wall on all leaves. The modulus of elasticity of the outer leaves remains constant $\left(\mathrm{E}_{1}=\right.$ $3500 \mathrm{MPa})$ while the modulus of elasticity of the inner leaf $\left(\mathrm{E}_{2}\right)$ varies. The response of the structure is calculated for three ratios of modulus of elasticity $\left(\mathrm{E}_{2} / \mathrm{E}_{1}\right)$ : $0.2,0.5$, and 0.8 . The intensity of the compressive load increases monotonically from 0.3 $\mathrm{MPa}$ up to $10 \mathrm{MPa}$. Figure $4 \mathrm{a}$ depicts the vertical compressive strains on the leaves for $\mathrm{E}_{2} / \mathrm{E}_{1}=0.2$ and load intensity $5 \mathrm{MPa}$. High strains occur in the inner leaf at the top part of the wall and are reduced gradually at lower heights. As the modulus of elasticity of the inner leaf increases $\left(\mathrm{E}_{2} / \mathrm{E}_{1}=0.8\right)$ the strains appear more uniform and smaller (Fig. 4b).

In order to interpret the significance of the characteristics of the properties of the wall for the response of the structure and to ascertain to what extent the variations of the properties influence the response of the wall, a stress-strain diagram is obtained for an element located at the middle-top of the inner leaf. It is observed that the modulus of elasticity of the inner leaf plays an important role on the response of the wall (Fig. 5). At low compressive loads the modulus of elasticity does not affect significantly the response. As the load increases, the influence of the modulus of elasticity on the response of the structure increases. For low values of $\mathrm{E}_{2} / \mathrm{E}_{1}=0.2$ the inner leaf deforms more, producing higher strains. As the modulus of elasticity increases the wall becomes stiffer and the strains are reduced. 


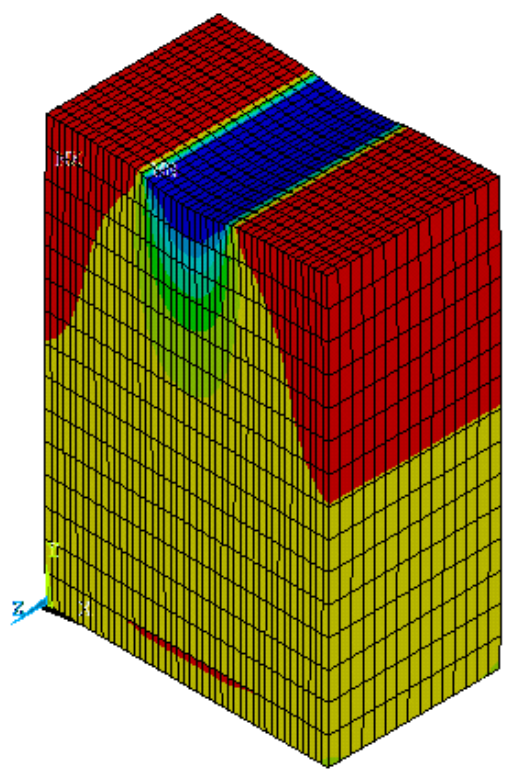

(a)

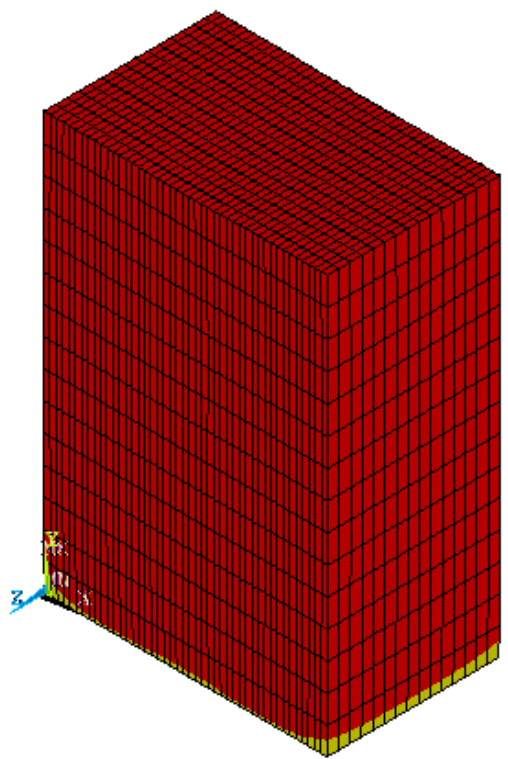

(b)

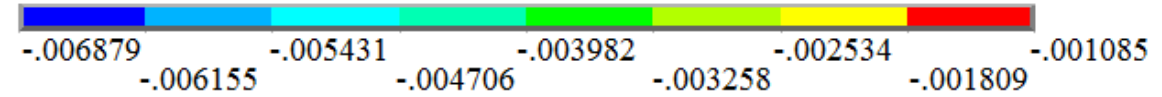

Fig. 4: Vertical strains (load $=5 \mathrm{MPa})$ : a) $\mathrm{E}_{2} / \mathrm{E}_{1}=0.2 ;$ b) $\mathrm{E}_{2} / \mathrm{E}_{1}=0.8$.

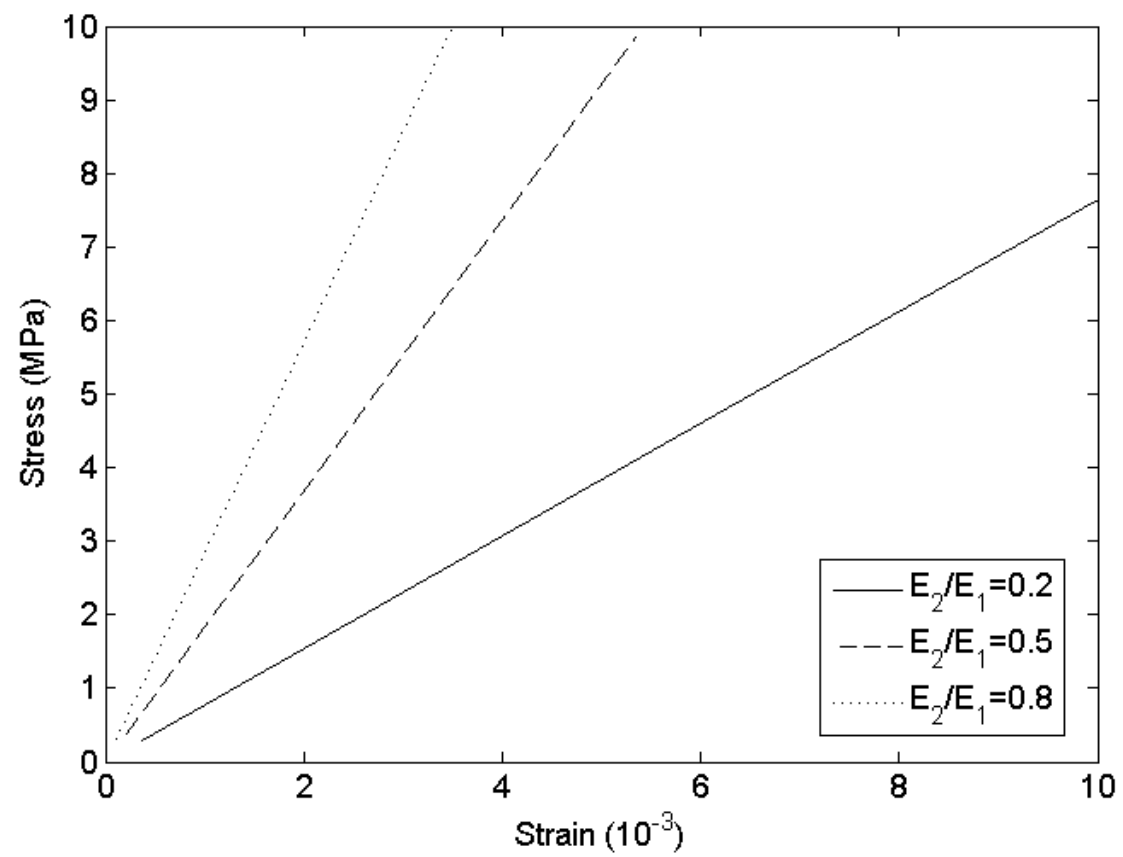

Fig. 5: Stress-strain diagram ( $\mathrm{E}_{1}=$ const.) for an element located at the middle-top of the inner leaf.

\subsection{Combined load}

The influence of the modulus of elasticity on the behavior of the multi-leaf is also examined for compressive and shear loads applied at the top of the wall on all leaves. The compressive load is assumed constant ( $5 \mathrm{MPa}$ ) while the shear loads vary from $5 \mathrm{kN} / \mathrm{m}^{2}$ to $30 \mathrm{kN} / \mathrm{m}^{2}$. A stress-strain diagram is obtained for an element located at the middle-top of the inner leaf. The influence of the modulus of elasticity of the inner leaf increases with increasing shear loads (Fig. 6). 
The response is higher for small values of $E_{2} / E_{1}$ as the inner leaf deforms more producing higher strains. As the modulus of elasticity increases the wall becomes stiffer and the strains are reduced. The existence of the shear load changes the response to smaller strains. At higher values of $\mathrm{E}_{2} / \mathrm{E}_{1}$ the straight lines of the response are closer to each other reducing the influence of the modulus of elasticity on the behavior of the wall.

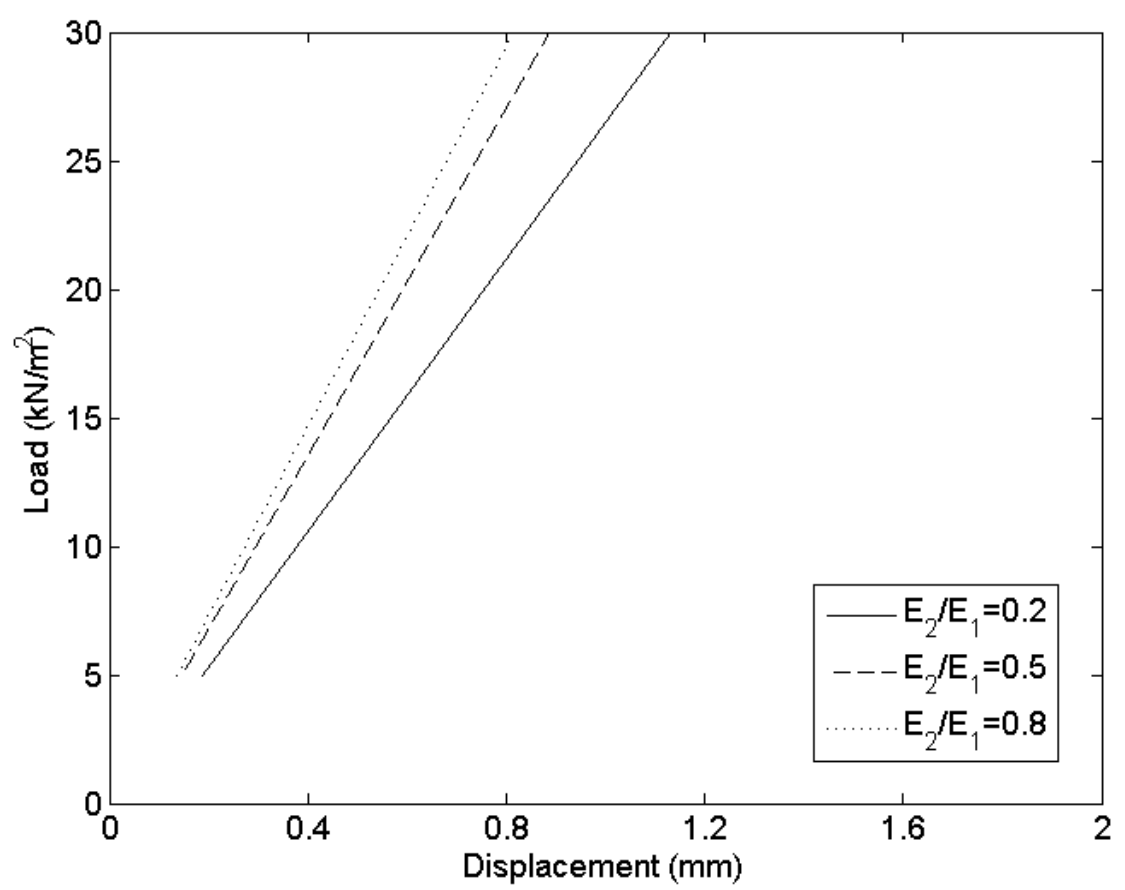

Fig. 6: Stress-strain diagram ( $\mathrm{E}_{1}=$ const.) for an element located at the middle-top of the inner leaf for combined loading conditions.

\section{Conclusions}

Multi-leaf walls can be found in many historic structures and have often experienced in the past extensive damage due to lack of proper connection of the leaves, the weakness of the inner layer and the deterioration of mortar between the joints. The understanding of the behavior of this complex structure can lead to better assessment of the damage that has already occurred and can be used to predict its future behavior for different loading conditions. This work examined the influence of the properties for the response of the structure for different loading conditions. The modulus of elasticity of the inner layer plays an important role for the response of the wall especially when high compressive load is applied. Low values of the modulus of elasticity of the inner leaf produce higher strains in all loading conditions considered.

\section{References}

[1] M. R. Valluzzi, F. da Porto and C. Modena, "Behaviour of multi-leaf stone masonry strengthened by different intervention techniques", Historical Constructions, 2001, pp. 1023-1032.

[2] M. A. Ramalho, A. Taliercio, A. Anzani, L. Binda, E. Papa , "A numerical model for the description of the nonlinear behaviour of multi-leaf masonry walls., Advances in Engineering Software, Vol. 39, 2008, pp. 249-257.

[3] L. Bindau, A. Saisi, C. Tiraboschi, "Investigation procedures for the diagnosis of historic masonries", Construction and Building Materials, Vol. 14, 2000, pp. 199-233.

[4] P. G. Asteris, "On the structural analysis and seismic protection of historical masonry structures", The Open Construction and Building Technology Journal, Vol. 2, 2008, pp. 124-133.

[5] L. Binda, J. Pina-Henriques, A. Anzani, A. Fontana, P. B. Lourenco, "A contribution for the understanding of load-transfer masonry walls: Testing and modeling”, Engineering Structures, Vol. 28, 2006, pp. 1132-1148. 